\title{
PRESENTACIÓN DE LA PELÍCULA "LUCES DE BOHEMIA"
}

\author{
Rodolfo Cardona \\ Boston University
}

1. En Luces de Bohemia Valle-Inclán presenta una serie de incidentes que el protagonista, el poeta ciego Max Estrella, encuentra en su camino, casi accidentalmente. Por medio de estos incidentes Max toma conciencia, gradualmente, de cosas que anteriormente no habían atraído su atención a causa de su continua preocupación por lo que él piensa es su propia "tragedia." Los incidentes que le acosan en su camino están relacionados con las condiciones económicas, políticas y sociales que sufre su país en ese preciso momento de su historia y que son la causa de las huelgas, motines y desórdenes públicos que él vive. A través de esta toma de conciencia el protagonista cambia de actitud o de postura: de la de un artista ajeno a su entrono, a la de un participante comprometido y preocupado con lo que está sucediendo a su alrededor. Al final, antes de morir a causa de su debilidad y de haberse expuesto a las inclemencias del relente madrileño mientras rodaba borracho por las calles en un Madrid encendido en tumultos y disturbios callejeros entre el pueblo y la autoridad, Max tiene su momento de iluminación, una como epifanía, durante la cual descubre la manera de expresar, como artista, la situación histórica de su país; una situación que, al contrario de lo que creen sus paisanos, no es trágica sino más bien una extraña mezcla de farsa grotesca con ribetes de tragedia. Llega a creer que la única manera de expresar fielmente esta situación, para poder señalarle a sus compatriotas su absurdo grotesco, si bien con algunos toques trágicos, es ponerle delante un espejo en el que puedan verse tal como son. Sin embargo, un espejo ordinario —el que ha sido utilizado durante siglos como la clásica metáfora para expresar cómo el arte refleja la realidad-impartiría a esa situación un orden que distorcionaría su verdadera naturaleza caótica y absurda. Max concluye entonces que la única manera en que un espejo pueda reflejar, con perfección matemática, esa realidad caótica y absurda, es si el espejo es cóncavo. Un espejo cóncavo distorciona lo que refleja de la manera precisa necesaria para poder aplicar la metáfora mimética de la reflexión a una condición histórica como la que existe en su país y que él ha vivido durante las últimas horas en su odisea madrileña. Por consiguiente, el espejo cóncavo es el único que puede ofrecerle al artista la visión exacta que le permitirá presentar al público el material histórico que él desea reflejar. Las imágenes reflejadas en el espejo cóncavo son, claro, grotescas. Por esta razón el artista escoge la palabra "esperpento" para denominar esta visión grotesca y es así como crea 
un término genérico descriptivo de esta nueva "estética" que pretende lograr una reacción crítica hacia y no una identificación con, la realidad reflejada.

2. Las consideraciones tóricas que he apuntado concernientes a la creación del esperpento, suceden dentro del primer esperpento escrito por Valle-Inclán. En otra ocasión expuso sus nuevas teorías estéticas que le llevaron a crear un teatro distanciado, más o menos en estas palabras (cito de memoria) : Hay tres maneras de ver el mundo artísticamente: de rodillas, en pie, y desde el aire. Cuando el artista ve a sus personajes desde la primera posición —la más antigua de las tres- cubre a sus héroes con un manto de superioridad con respecto a sí mismo, convirtiéndolos en semidioses. Desde la segunda posición el artista mira a sus personajes como si estos fueran gente como nosotros, como él, como si fuesen nuestros dobles. Esta es la visión que ha prosperado más en nuestra literatura.

Es la visión con que Shakespeare creó sus obras. Hay, empero, una tercera manera que es la de mirar el mundo y sus gentes desde lo alto, como si estuviésemos elevados en el aire, lo que le permite al artista ver a sus personajes como si fueran inferiores a él, quien los mira con una visión irónica. Esta es una manera muy española de mirar al mundo, la manera del demiurgo quien cree que está hecho de un material distinto del de sus personajes. Quevedo utilizó esta manera, así como Cervantes antes que él. Y Goya la estableció definitivamente en sus pinturas. Y termina diciendo don Ramón: Fue la consideración de esta tercera manera la que me condujo a cambiar drásticamente mi literatrura y a que escribiera los esperpentos; el género literario que he bautizado con el nombre de esperpento.

3. Si ahora volvemos a Luces de Bohemia, no hay duda de que en este esperpento ValleInclán se propone presentar una serie de experiencias por medio de las cuales el protagonista, como apunté al principio, toma conciencia y se compromete vis à vis la circunstancia política y social de la historia de España durante la década de los años 20. Algunas de estas experiencias las vive el protagonista como testigo pero otras las experimenta en sí mismo como participante. La visión utilizada por Valle-Inclán al presentar estas experiencias - todas derivadas de la realidad, es decir, de situaciones históricas documentables- es la visión que obtuvo al aplicar la tercera manera de ver el mundo artísticamente. En otras palabras, no busca crear una identificación con esos sucesos ni como autor ni, menos aún como medio para inspirar un deseo de identificación de parte del público. El éxito de los esperpentos depende, precisamente, de la recreación, para beneficio del público, del mismo distanciamiento que él utilizó cuando los escribió. Es esto, entonces, lo que presenta un problema para el crítico, pero más aún para el director de escena $\multimap$ de una película, en este caso- y para los actores.

El error del director y del guionista de la versión cinematográfica de Luces de Bohemia es haber creído que comprendía bien la idea del distanciamiento en los esperpentos y tratar de ser "más papista que el Papa" añadiendo, gratuitamente, un grado más de este distanciamiento al crear un narrador interno quien recrea o reconstituye para el público las experiencias de Max en las últimas horas antes de su muerte. La película empieza con el funeral de Max y con uno de los jóvenes modernistas asistentes a él quien, identificándose con la figura del poeta ciego, desea reconstruir qué le llevó a esa muerte. Al hacer esto desvirtúa totalmente lo que es la escencia del esperpento tal y como he tratado de explicarla y, peor aún, le quita a Max la motivación que le lleva a la concepción de esta visión esperpéntica de la historia. Esta película es útil por dos razones: primero, nos muestra el camino equivocado para la realización de un 
esperpento y, particularmente de este esperpento que Valle-Inclán titula con gran acierto Luces de Bohemia; y en segundo lugar, porque a pesar de sus defectos, recrea muy bien, visualmente, el ambiente del Madrid en el que Max Estrella vivió los sucesos que le llevaron a la concepción de la nueva estética.

\section{Presentación del mantaje de la escena XI de Luces de Bohemia}

1. Teniendo en cuenta lo que dije sobre la creación del esperpento dentro de la obra Luces de Bohemia y sobre la estética desarrollada por Valle-Inclán para la creación de sus esperpentos, la de la tercera manera de ver el mundo artísticamente, es decir, la manera del distanciamiento, nos preguntamos cómo podría representarse una escena como la oncena de Luces sin desvirtuar lo que Valle-Inclán se propuso al escribir este esperpento y todos sus esperpentos y que tan claramente ha expresado para no dejar equívocos.

En la escena XI de esta obra Max Estrella es testigo presencial de una muerte trágica: la de un niño de pecho que, en brazos de su madre, es mortalmente herido por una bala perdida.

$\mathrm{Al}$ entrar en escena Max encuentra a la madre en la calle: "una mujer despechugada y ronca tiene en los brazos a un niño muerto, la sien traspasada por el agujero de una bala," reza la acotación. La escena contiene todos los ingredientes para lo que los griegos llaman pathos y que puede considerarse, en términos normales utilizados hoy día por la gente, tragedia pura. ¿Qué puede ser más trágico, en estos términos, que la muerte violenta de un niño inocente?

Ahora bien, podemos preguntarnos: ¿Se ha olvidado Valle-Inclán de su "tercera manera" y ha resbalado aquí a la segunda, la manera de Shakespeare quien mira las acciones humanas con compasión? Esto es lo que afirman algunos críticos, incluso el conocido dramaturgo Buero Vallejo. En vez de una escena esperpéntica, como corresponderia dentro de un esperpento como Luces ¿tenemos aquí una escena trágica sin más?

Yo creo que no. Yo sugiero que Valle-Inclán ha utilizado conscientemente esta "escena callejera" como la última experiencia sufrida por Max como testigo antes de su final momento de iluminación, cuando, a pesar de ser ciego, llega a ver claramente la vida que le rodea como un "círculo infernal," un "círculo dantesco." Yo creo sigificativo el hecho que hacia el final de esta escena Max declara "me muero de hambre, satisfecho de no haber llevado una triste velilla en la trágica mojiganga." Se refiere a la Historia de España, como se puede verificar en el contexto en que aparece la frase citada. Si utiliza este oximorón - esta "armonía de contrarios" "trágica mojiganga"- en esta escena, es precisamente porque el contexto en el que ocurre, la muerte trágica del niño, es tan risiblemente absurdo, que convierte la experiencia de esta muerte, y con ella la historia contemporánea de España, en una "trágica mojiganga."

2. Así y todo, cuando he visto esta "escena callejera" en montajes de Luces de Bohemia, no ha sido siempre posible para los actores dejar de crear un sentimiento de identificación de parte del público hacia la situación dramatizada. Los comentarios fatuos de los que rodean a la madre que sufre no son suficientemente destacados en la escenificación para reducir el impacto trágico intrínseco a la situación y así lograr que su dramatización coincida con la estética del esperpento tal y como Valle-Inclán nos la explica. Es entonces indispensable que director y actores tengan una mejor conciencia de lo que es el teatro distanciado, el teatro dialéctico, para poder así representar esta escena con la que culmina la serie de experiencias que llevan a Max 
Estrella a la creación del esperpento. Si se llega a una total comprensión de lo que se propuso don Ramón podrían, creo yo, representarse la escena con la mezcla necesaria de tragedia y de farsa para evitar el peligro de la identificación sentimental, la mayor enemiga del esperpento.

3. Consideremos una vez más el propósito de la secuencia de escenas que conforman esta obra. Si el propósito es representar ante el público aspectos indignantes de la historia de España y mostrar esta historia en toda su realidad grotesca y tragifársica, de modo que, una vez que el público los haya visto bajo esta luz deje de considerarse víctima de un destino trágico y, en cambio, se vea como víctima del engaño de una situación política que puede cambiarse, es obvio, entonces que la representación escénica debe estar a tono con ese propósito.

Valle-Inclán, en su "escena callejera" presenta, dentro de su obra Luces de Bohemia (y no como una consieración teórica aparte, como en la famosa "escena callejera" de Brecht) un modelo de lo que un esperpento debe ser y cómo debe actuarse.

Consideren el importante dato que el principal testigo de los sucesos presentados dentro de este esperpento es un poeta ciego, Max Estrella. Tiene un compinche, un viejo cínico, Don Latino, que le acompaña a todas partes y quien, la mayor parte del tiempo, tiene que interpretar para Max lo que está sucediendo a su alrededor. Así entonces, en la "escena callejera" que estamos considerando, los dos incidentes principales que ocurren en ella - la muerte accidental del niño y la "ejecución" de un preso anarquista por la autoridad con la excusa de que quería escaparse, la famosa "ley de fuga"-o ya han sucedido cuando la escena empieza o suceden lejos del lugar donde ocurre la escena. Por consiguiente, estos sucesos tienen que ser narrados. Los incidentes, entonces, son presentados principalmente por medio de sus resultados — los gritos rabiosos de la madre que Max escucha, o el ruido de los disparos que se escuhan fuera de la escena, cuya causa es explicada para beneficio de los presentes (y del público) por el sereno. Max necesita que su compinche le interprete las cosas que él escucha pero que no puede ver; otras cosas las interpreta por medio de los comentarios de los vecinos presentes. Estos comentarios los hacen personas del barrio que han sido testigos presenciales del primer incidente y tratan de dar su versión de lo que sucedió, particularmente con respecto a quién tuvo la culpa. Así, los sucesos trágicos que han tomado lugar en esta escena están recubiertos de un contexto que les resta dignidad trágica. Los sucesos se comentan en términos completamente fatuos o con ribetes de cinismo. Fíjense en los comentarios del Empeñista, del Guardia, del Tabernero, del Retirado, todos presentes cuando la bala perdida mata al niño; y luego los comentarios cínicos de Don Latino quien cree y dice que "Hay mucho de teatro" en la "cólera trágica" con que grita la madre del niño. Más tarde, cuando Max, indignado por el asesinato a sangre fría del anarquista invita a su amigo a saltar desde el Viaducto ("Te invito a regenerarte con un vuelo"), Latino desinfla su postura trágica con el comentario: “¡Max, no te pongas estupendo!”, con el que finaliza esta escena.

4. Lo que hace Valle-Inclán es desplazar los incidentes trágicos lo más posible del público: primero, al decidir que estos sean narrados en vez de presentados directamente; segundo, al hacer que estos incidentes sean comentados con varios grados de distanciamiento, desde el más cercano a la simpatía que hace la Vieja al decirle a la madre "iTen prudencia, Romualda!”, hasta el comentario cínico de Latino "Hay mucho de teatro;" tercero, al obligar a Max, a causa de su ceguera, a pedir que le interpreten lo que está sucediendo; y finalmente, al hacer que Max se indigne profundamente, liberando así al público de una indignación identificadora, y que 
Max también asuma una postura trágica que, como hemos visto, Latino inmediatemente desinfla con el comentario “iMax, no te pongas estupendo!" Todos estos dispositivos escénicos ayudan a crear un distanciamiento entre lo que ha sucedido y el público y, a la vez, impiden que éste se identifique con los sucesos trágicos. Cuando el suceso es percibido por el público ya ha dejado de ser puramente trágico; es decir, es una tragedia rodeada de idioteces, farsa, hipocrecía, egoísmo y absurdos. Así entonces, al elemento trágico, indiscutiblemente presente, se le quita toda posibilidad de dignidad. Después de esta "escena callejera" es por fin posible que Max llegue a la misma conclusión a la que ha llegado el público: que la tragedia de España no es tragedia sino un esperpento y que su propia vida es una "trágica mojiganga," una mezcla de elementos dispares.

5. Debemos colegir, entonces, que los elementos necesarios para llegar a esta interpretación de la historia de España, tanto para Max como para el público, están presentes y dramatizados en la "escena callejera," la oncena de la obra, una escena que requiere un tipo de actuación distanciada para poder así destacar correctamente las intenciones presentes en ella. De otra forma existe el peligro de convertir esta escena en algo lacrimoso y así destruir el esperpento. Covendría que los actores que van a representarla tuviesen muy en mente el artículo de Brecht "Escena callejera, un modelo básico para el Teatro Épico," y los ejercicios que allí recominda, como preparación para actuar en cualquier esperpento de Valle-Inclán. 
4 